\title{
Insecticide resistance, fitness and susceptibility to Zika infection of an interbred Aedes aegypti population from Rio de Janeiro, Brazil
}

\author{
Carlucio Rocha dos Santos ${ }^{1,2,3^{*}}$, Cynara de Melo Rodovalho ${ }^{2,3}$, Willy Jablonka ${ }^{1}$, Ademir Jesus Martins ${ }^{2,3}$, \\ José Bento Pereira Lima ${ }^{2,3}$, Luciana dos Santos Dias ${ }^{2,3}$, Mário Alberto Cardoso da Silva Neto \\ and Georgia Correa Atella ${ }^{4}$
}

\begin{abstract}
Background: Aedes aegypti is a vector of high relevance, since it transmits several arboviruses, including dengue, chikungunya and Zika. Studies on vector biology are usually conducted with laboratory strains presenting a divergent genetic composition from field populations. This may impair vector control policies that were based on laboratory observations employing only long maintained laboratory strains. In the present study we characterized a laboratory strain interbreed with Ae. aegypti collected from five different localities in Rio de Janeiro (Aedes Rio), for insecticide resistance (IR), IR mechanisms, fitness and Zika virus infection.

Methods: We compared the recently established Aedes Rio with the laboratory reference strain Rockefeller. Insecticide resistance (deltamethrin, malathion and temephos), activity of metabolic resistance enzymes and kdr mutation frequency were determined. Some life table parameters (longevity, blood-feeding, number and egg viability) and Zika virus susceptibility was also determined.
\end{abstract}

Results: Aedes Rio showed resistance to deltamethrin (resistance ratio, $R_{50}=32.6$ ) and temephos $\left(R_{50}=7.0\right)$ and elevated activity of glutathione S-transferase (GST) and esterases ( $\alpha$-EST and pNPA-EST), but not acetylcholinesterase (AChE). In total, $92.1 \%$ of males genotyped for kdr presented a "resistant" genotype. Weekly blood-fed females from both strains, presented reduced mortality compared to sucrose-fed mosquitoes; however, Aedes Rio blood-fed females did not live as long (mean lifespan: Rockefeller $=70 \pm 3.07$; Aedes Rio $=53.5 \pm 2.16$ days). There were no differences between strains in relation to blood-feeding and number of eggs, but Aedes Rio eggs presented reduced viability (mean hatch: Rockefeller $=77.79 \pm 1.4 \%$; Aedes Rio $=58.57 \pm 1.77 \%$ ). Zika virus infection (plaque-forming unit, PFU) was similar in both strains (mean PFU \pm SE: Aedes Rio: $4.53 \times 10^{4} \pm 1.14 \times 10^{4} \mathrm{PFU}$; Rockefeller: $2.02 \times 10^{4} \pm 0.71 \times 10^{4} \mathrm{PFU}$ ).

Conclusion: Selected conditions in the field, such as IR mechanisms, may result in pleiotropic effects that interfere in general physiology of the insect. Therefore, it is important to well characterize field populations to be tested in parallel with laboratory reference strains. This practice would improve the significance of laboratory tests for vector control methods.

Keywords: Aedes aegypti, Mosquito, Insecticide resistance, Fitness

\footnotetext{
*Correspondence: carluciorsantos@gmail.com

${ }^{1}$ Laboratório de Sinalização Celular Programa de Biologia Molecular

e Biotecnologia, Instituto de Bioquímica Médica Leopoldo de Meis,

Universidade Federal do Rio de Janeiro, Rio de Janeiro, RJ, Brazil

Full list of author information is available at the end of the article
}

c) The Author(s) 2020. This article is licensed under a Creative Commons Attribution 4.0 International License, which permits use, sharing, adaptation, distribution and reproduction in any medium or format, as long as you give appropriate credit to the original author(s) and the source, provide a link to the Creative Commons licence, and indicate if changes were made. The images or other third party material in this article are included in the article's Creative Commons licence, unless indicated otherwise in a credit line to the material. If material is not included in the article's Creative Commons licence and your intended use is not permitted by statutory regulation or exceeds the permitted use, you will need to obtain permission directly from the copyright holder. To view a copy of this licence, visit http://creativeco mmons.org/licenses/by/4.0/. The Creative Commons Public Domain Dedication waiver (http://creativecommons.org/publicdomain/ zero/1.0/) applies to the data made available in this article, unless otherwise stated in a credit line to the data. 


\section{Background}

The mosquito Aedes (Stegomyia) aegypti (Linnaeus, 1762) is a cosmotropical species distributed through tropical and subtropical regions near human settlements [1-3]. This mosquito displays significant medical importance as a vector of several arboviruses, such as dengue virus, causing the most predominant arthropod-borne viral disease that affects humans [4]. Besides dengue virus, Ae. aegypti also transmits chikungunya, yellow fever and Zika viruses. The availability of only symptomatic treatment and the absence of vaccines for most of the aforementioned arboviruses, has led to the dependence of current disease control policies on vector control. However, sociocultural issues and economic problems impair infrastructure investments, a key approach to mosquito control, leading public policies to rely mainly on synthetic insecticides. Their overuse, however, may result in increased vector insecticide resistance, reducing the efficacy of this strategy $[5,6]$.

Several studies have been carried out aiming at improving the knowledge about vector biology, development of new classes of insecticides and novel methods of control, considering either suppression of population densities or their substitution for strains not able to transmit arboviruses [7]. Laboratory research on vectors is essential for understanding their role in pathogen proliferation and transmission, as well as for the development of enhanced vector control strategies [8,9]. Studies underlining such assessments usually rely on strains long maintained in laboratory colonies. This is very convenient, since such strains eventually become highly adapted to laboratory conditions and are thus easily maintained. In addition, they can be shared among different laboratories and employed as a reference for reproducibility when standard conditions are followed. On the other hand, colonization and inbreeding processes lead to genetic bottlenecks, with consequent decreases in heterozygosity, as observed by microsatellite allelic richness analyses [10]. The pressure for laboratory adaptation and loss of characteristics selected for specific conditions in the field may result in the overall genetic composition, and consequently of diversified phenotypic traits, distinct from those of field populations [11-17]. Such phenotypic differences lead to differential fitness under a controlled environment, resulting in different responses in comparison to field populations [18-22]. This can be observed with insecticide resistance populations, which generally display reduced fitness under laboratory conditions, due to selected physiological changes on structural molecules or because displacement of energy for increased production of protective molecules against those chemicals [23].
Indeed, resistance to insecticides, such as temephos and DDT, led to a significant reduction of fertility lifetable, blood-feeding and survival of Ae. aegypti and, ultimately, interfere with its vectorial capacity, a condition estimated through biological, ecological and behavioral parameters [24-26]. Moreover, field Ae. aegypti challenged with dengue virus present a significant infection rate variability compared to laboratory-reared strains, highlighting that field selection can also influence mosquito vector competence $[8,27]$.

Assessments concerning the development and reproduction aspects of vector populations have the potential to generate important data for combat policies and new control studies, leading to more accurate results. However, few studies have accessed the overall fitness aspects of field populations when evaluating vector control strategies $[9,26,28]$. Therefore, the present study aims to evaluate the insecticide resistance profile, fitness traits and vector competence to Zika virus in a field-representative Ae. aegypti population from Rio de Janeiro State, in comparison to a laboratory mosquito strain.

\section{Methods \\ Aedes Rio population}

The establishment of the Aedes Rio population was carried out with ovitraps randomly installed on house grounds across five localities in Rio de Janeiro (50 ovitraps in each location): Paquetá $\left(22^{\circ} 49^{\prime} 27^{\prime \prime} \mathrm{S}\right.$, $\left.43^{\circ} 05^{\prime} 52^{\prime \prime} \mathrm{W}\right)$, Niterói $\left(22^{\circ} 53^{\prime} 14^{\prime \prime} \mathrm{S}, 43^{\circ} 06^{\prime} 44^{\prime \prime} \mathrm{W}\right)$, Praça XV $\left(22^{\circ} 54^{\prime} 18^{\prime \prime} \mathrm{S}, 43^{\circ} 10^{\prime} 19^{\prime \prime} \mathrm{W}\right)$, São Gonçalo $\left(22^{\circ} 46^{\prime} 45^{\prime \prime} \mathrm{S}\right.$, $\left.43^{\circ} 03^{\prime} 48^{\prime \prime} \mathrm{W}\right)$ and Ilha do Governador $\left(22^{\circ} 48^{\prime} 23^{\prime \prime} \mathrm{S}\right.$, $\left.43^{\circ} 11^{\prime} 46^{\prime \prime} \mathrm{W}\right)$. Hatching of the eggs present on the paddles was induced in dechlorinated water containing $1 \mathrm{~g}$ of cat food (Friskies; Purina, Vevey, Switzerland). After adult emergence, Ae. aegypti mosquitoes were screened and separated by locality. Females were fed on blood in order to obtain eggs.

Eggs from each locality were hatched and the larvae were raised as described previously. A total of 20 males and 20 virgin females from each location were placed in small cages to mate, totalling 25 cages (Fig. 1). After five days of free mating, females fed on blood and all mosquitoes were combined in a single cage in order to obtain a collective oviposition, generating Aedes Rio F1 eggs.

Aedes Rio F1 eggs were raised and two cages were assembled, each containing 500 males and 500 females. After 5 days of free mating, the females were fed on blood and all mosquitoes were combined in a single cage in order to obtain Aedes Rio F2 eggs. After the establishment of the Aedes Rio population, the following generations were used for the experiments. 


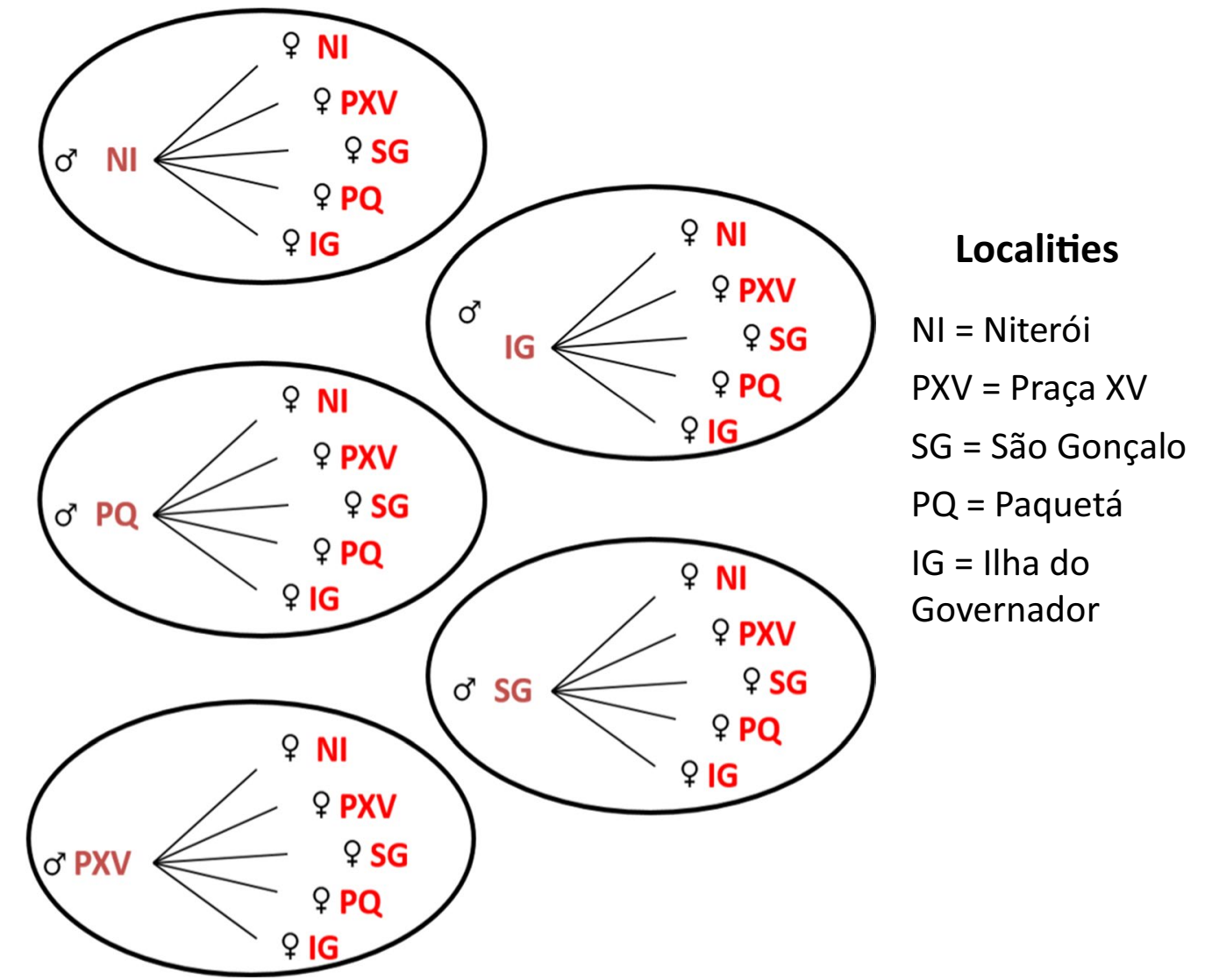

Fig. 1 Mating scheme to obtain the Aedes Rio F1 population. A total of 25 cages were assembled, each one containing 20 males and 20 virgin females from each locality

\section{Mosquito rearing}

All experiments were conducted with Aedes Rio F4, except for Zika virus (ZIKV) tests, which were performed with Aedes Rio F6. Comparisons were carried out with the Rockefeller strain, an widely used mosquito strain brought from the USA by the Brazilian Ministry of Health in the 1990s and distributed to Brazilian laboratories; since then, this strain has been used for insecticide tests and physiological studies.

The eggs were allowed to hatch for $2 \mathrm{~h}$ and approximately 300 larvae were reared in plastic trays containing $1 \mathrm{l}$ of dechlorinated water and $1 \mathrm{~g}$ of cat food (Friskies; Purina). The food was provided every three days until pupation. The pupae were separated in plastic $50 \mathrm{ml}$ cups and placed in cardboard cages until adult emergence. The larvae were kept in a biological oxygen demand incubator (BOD) at $26.5 \pm 1{ }^{\circ} \mathrm{C}$, with a relative humidity of $70 \pm 10 \%$ and a $12 \mathrm{~h}$ photoperiod. Adults were maintained in a controlled environment at $26 \pm 1{ }^{\circ} \mathrm{C}$ and a relative humidity of $70 \pm 10 \%$.

\section{Insecticide resistance assays}

Dose-response bioassays were performed for the determination of the resistance profile to the organophosphate temephos of Aedes Rio larvae and the adult resistance profile to the organophosphate malathion and the pyrethroid deltamethrin used in control policies. Mosquitoes from the susceptible Rockefeller strain were used as reference and resistance ratios (RR) were calculated. The assays were performed following the WHO guidelines $[29,30]$ with slight modifications, and the WHO tubes methodology containing insecticide-impregnated papers was applied for the adult evaluation. Briefly, for larvae, 20 third-stage larvae (L3) were placed in $50 \mathrm{ml}$ plastic cups, totalling four replicates (80 exposed larvae) for each insecticide concentration. A total of 11 increasing concentrations (ranging from 0.012 to $0.072 \mathrm{mg} / \mathrm{l}$ ) in a final volume of $100 \mathrm{ml}$ per glass were applied, and four glasses without insecticide were used as the controls. After $24 \mathrm{~h}$ of insecticide exposure, mortality rates were observed and recorded. A total of three bioassays were performed on different days. 
For the adult tests, insecticide-impregnated papers were prepared at the Laboratório de Fisiologia e Controle de Artrópodes Vetores, Laficave, Brazil. Two control tube papers were impregnated only with the silicone vehicle. The papers were impregnated with insecticides at 10 different concentrations, as follows: malathion ranged from 0.05 to $0.5 \mathrm{~g} / \mathrm{m}^{2}$ and deltamethrin, from 10.4 to $114.8 \mathrm{mg} /$ $\mathrm{m}^{2}$. Three replicates were evaluated for each concentration. A total of 20 non-blood-fed females 3-5 days-old were transferred to each tube. All females remained in the test tubes for $1 \mathrm{~h}$. After this period, the females were transferred and maintained in resting tubes (without any insecticide) for $24 \mathrm{~h}$ and mortality rates were observed and recorded. The assays were repeated three times, on different days. All bioassays were performed under controlled temperature and humidity conditions $\left(26 \pm 2{ }^{\circ} \mathrm{C}\right.$ and $70 \pm 10 \%$, respectively), and a sugar solution was offered during the period the organisms remained in the resting tubes.

\section{Enzymatic assays}

The activity of the main enzymes related to metabolic resistance, glutathione-S-transferases (GST), mixed function oxidases (MFO) and esterases (EST), were evaluated in one-day-old adult females and males. The procedures and analysis used are described in Valle et al. [31] and Viana-Medeiros et al. [32]. Briefly, the enzymatic assays were performed in duplicate in 96-well microtiter plates. Concerning esterases, the substrates $\alpha$-naphthyl, $\beta$-naphthyl and $p$-nitrophenyl acetate (herein referred to as $\alpha$-EST, $\beta$-EST and $p$ NPA-EST) were employed. MFO was indirectly measured, whereas for acetylcholinesterase (AChE), both total activity and activity inhibited by propoxur were assayed. To calculate specific enzymatic activities, the total protein content of each specimen was quantified using a Bio-Rad protein assay/dye reagent concentrate (Bio-Rad, Hercules, USA). Standard susceptible profiles were taken from Rockefeller strain values. Mosquitoes from this reference strain were also included on all plates as an internal control. Enzyme activities were classified according to previously established criteria [33], as follows: after calculating the 99th percentile for the Rockefeller strain, the rate of specimens above this value was estimated for each enzyme and population.
Activities were classified as unaltered, altered or highly altered when this rate was determined as $<15 \%$, at $15-50$ or $>50 \%$, respectively.

\section{Molecular assay}

DNA of 38 males was individually extracted. The mosquitoes were homogenised in $500 \mu \mathrm{l}$ of a TNES buffer (Tris $50 \mathrm{mM}, \mathrm{NaCl} 400 \mathrm{mM}$, EDTA $20 \mathrm{mM}$ and SDS 0.5\%) and incubated with $0.2 \mathrm{mg} / \mathrm{l}$ proteinase $\mathrm{K}$ at $56{ }^{\circ} \mathrm{C}$ for $3 \mathrm{~h}$. Then, precipitations and alcohol washes were performed, as described in Martins et al. [34].

SNP genotyping assay was used to verify the presence of knockdown resistance $(k d r)$ mutations $1016\left(\mathrm{Val}^{+}\right.$ and $\mathrm{Ile}^{k d r}$ ) and 1534 ( $\mathrm{Phe}^{+}$and $\mathrm{Cys}^{k d r}$ ) in the voltagegated sodium channel gene $\left(A a N a_{V}\right)$. The customized TaqMan Genotyping Assay method (Thermo Fisher Scientific, Waltham, USA) was performed in independent reactions for each site. Primers and probes are listed in Table 1 . The reactions were prepared in $10 \mu \mathrm{l}$, containing $1 \mu \mathrm{l}$ of DNA ( $10 \mathrm{ng}), 1 \times$ TaqMan Genotyping Master Mix and TaqMan Assay, combining $0.5 \times$ of primers and $1 \times$ of probes for the 1534 and 1016 sites, in a 96-well microplate. As positive controls, the Rockefeller strain (SS), Rock- $k d r$ strain (RR) [35], and a mix with equimolar amounts of Rockefeller and Rock-kdr DNA (RS) were used. The thermocycling conditions followed the manufacturer instructions (TaqMan Genotyping Assay; Thermo Fisher Scientific) and the reactions were conducted using a real time QuantStudio 6 thermocycler (Thermo Fisher Scientific). As described elsewhere [36], the allelic and genotypic frequencies considered the 1016 and 1534 sites as a unique locus, and three alleles were constituted as $\mathrm{Na}_{\mathrm{V}} \mathrm{S}\left(1016 \mathrm{Val}^{+}+1534 \mathrm{Phe}^{+}\right), \mathrm{Na}_{\mathrm{V}} \mathrm{R} 1$ $\left(1016 \mathrm{Val}^{+}+1534 \mathrm{Cys}^{k d r}\right)$, and $\mathrm{Na}_{\mathrm{V}} \mathrm{R} 2\left(1016 \mathrm{Ile}^{k d r}+1534\right.$ $\mathrm{Cys}^{k d r}$ ).

Hardy-Weinberg equilibrium was assessed by the classical equation [37], the null hypothesis of equilibrium was checked by a Chi-square test with three degrees of freedom.

\section{Viral infection}

Zika viral stocks (Uganda strain) were propagated in C6/36 cells maintained in a Leibovitz- 15 medium supplemented with $10 \%$ fetal bovine serum, $1 \%$ penicillin/

Table 1 Primers and probes used in the SNP genotyping assay reactions

\begin{tabular}{ll}
\hline Primer sequence $\left(5^{\prime}-3^{\prime}\right)$ & ${\text { Probes }\left(5^{\prime}-3^{\prime}\right)}$ \\
\hline 1016for: CGTGCTAACCGACAAATTGTTTCC & $1016 V^{+}{ }^{+}$VIC-CCGCACAGATACTTA-NFQ \\
1016rev: GACAAAAGCAAGGCTAAGAAAAGGT & 1016 lle $^{\text {kdr }}$ FAM-CCCGCACAGGTACTTA-NFQ \\
1534for: CGAGACCAACATCTACATGTACCT & 1534 Phe ${ }^{+}$FAM-ACGACCCGAAGATGA-NFQ \\
1534rev: GATGATGACACCGATGAACAGATTC & 1534Cysdr VIC-AACGACCCGCAGATGA-NFQ \\
\hline
\end{tabular}


streptomycin, 1\% fungizone and HEPES buffer $2 \mathrm{mM}$. Culture supernatants containing viral particles were harvested, centrifuged at $4500 \times g$ for $10 \mathrm{~min}$ at $4{ }^{\circ} \mathrm{C}$, aliquoted, and stored at $-70{ }^{\circ} \mathrm{C}$ until use. Viral titers were determined by a plaque assay as $2 \times 10^{7} \mathrm{PFU} / \mathrm{ml}$. Plastic cages containing 2007 days-old Ae. aegypti mosquitoes (100 males and 100 females) were artificially fed with a 1:1 solution of heparinized and washed rabbit erythrocytes and DMEM culture medium containing ZIKV (final titer $1 \times 10^{7} \mathrm{PFU} / \mathrm{ml}$ ). Feeding was performed using water-jacketed artificial feeders maintained at $37{ }^{\circ} \mathrm{C}$ and sealed with parafilm membranes for approximately $1 \mathrm{~h}$ inside a Biosafety level 2 (BSL-2) insectary facility. The insects were starved for $12 \mathrm{~h}$ prior to feeding. Unfed mosquitoes were removed from the cages in all the experiments. Mosquitoes were then maintained under BSL-2 insectary conditions $\left(28{ }^{\circ} \mathrm{C}, \mathrm{L}: \mathrm{D} 12: 12 \mathrm{~h}, 70 \%\right.$ humidity) with access to a $10 \%$ sucrose solution. Females were then individually transferred to cryotubes 7 days post-blood meal and stored at $-70^{\circ} \mathrm{C}$ until assay.

A plaque assay was performed, for viral load evaluation, as previously described [38]. Briefly, Vero cells were cultured in complete DMEM media, supplemented with $10 \%$ fetal bovine serum, $1 \%$ penicillin/streptomycin, $1 \%$ L-glutamine, $1 \%$ fungizone and HEPES buffer $2 \mathrm{mM}$. One day prior to the assay, the cells were plated into 24-well plates at $70-80 \%$ confluence. The mosquitoes were homogenized using a homogenizer, centrifuged at $4000 \times$ $g$ for $10 \mathrm{~min}$ at $4{ }^{\circ} \mathrm{C}$ and four serial dilutions (10-fold) were performed. Each dilution was inoculated in a single well. The plates were then gently rocked for $15 \mathrm{~min}$ at RT and incubated for $45 \mathrm{~min}$ at $37^{\circ} \mathrm{C}$ and $5 \% \mathrm{CO}_{2}$. Finally, an overlay of DMEM containing $0.8 \%$ methylcellulose and $10 \%$ FBS was added to each well, and the plates were incubated for 5 days. To fix and stain the plates, the culture media was discarded and a 1:1 (v:v) methanol and acetone solution and $1 \%$ crystal violet was used. The plaque-forming units (PFU) were counted and corrected by the dilution factor. Mosquito viral loads (whole body PFU) and infection rates (IR: percentage of infected mosquitoes) were evaluated.

\section{Developmental and reproductive parameter evaluation Adult longevity}

Newly emerged adults (less than $24 \mathrm{~h}$ post-emergence from the pupae exuviae) were placed in small cylindrical cardboard cages containing 15 couples and fed one of two food diets: (i) two cages received sugar solution ad libitum as the only food source; and (ii) two cages, in addition to the sugar solution, received blood meals once a week (with prior $24 \mathrm{~h}$ withdrawal of the sugar solution); in this case, anesthetized guinea pigs were offered for blood-feeding for $30 \mathrm{~min}$. Mortality was scored every day until all mosquitoes were dead. This assay was performed four times.

\section{Blood-feeding}

The amount of ingested blood was assessed with approximately 5 days-old females. Mosquitoes were deprived of the sugar solution $24 \mathrm{~h}$ before the assay. Four pools of 10 females each were killed by ethyl acetate exposure and weighed on an analytical balance (APX - 200; Denver Instrument, New York, USA). Anesthetized guinea pigs were offered to another group of live females and, after $30 \mathrm{~min}$, an additional four groups of 10 fully engorged females were killed and weighed as described above. This assay was performed four times on different days.

\section{Oviposition and egg viability}

Oviposition was carried out three days after blood-feeding. Briefly, around 40 Aedes Rio females and 40 Rockefeller strain females were individually transferred to small Petri dishes $(9 \mathrm{~cm}$ in diameter) lined with filter paper on their lids. After moistening the filter paper with $3 \mathrm{ml}$ dechlorinated water, the Petri dishes remained in a BOD incubator with humidity set at $c .70 \%$; after two days, the number of egg-laying females and eggs were recorded. After the eggs had dried and were counted, $10 \mathrm{ml}$ of dechlorinated water was added to each plate. The eggs were allowed to hatch for two days and hatching larvae were counted. This assay was performed three times during different periods.

\section{Statistical analyses}

Lethal concentrations (LCs) were calculated using the Probit analysis available in the Polo-PC statistic package [39] and the RR were calculated by the division of the Aedes Rio LCs and the respective Rockefeller strain LCs. The populations were classified according to the criteria adopted by the WHO [30], in which populations with $R_{50}<5$ are considered susceptible, $R_{50}$ between 5 and 10 are considered populations displaying moderate resistance and $R_{50}>10$ are considered highly resistant.

Allelic and genotypic $k d r$ frequencies were calculated as described elsewhere [36]. The number of "resistant" genotypes was estimated as the sum of the homozygous and heterozygous $k d r$ genotypes (R1R1, R2R2 and R1R2) [40].

Lifespan comparisons were carried out by survivor curve and Mantel-Cox and Gehan-Breslow-Wilcoxon test calculations. Data normality was tested using the Shapiro-Wilk W test prior to additional statistical analyses. When data displayed a normal distribution, comparisons were performed by an unpaired 
Student's t-test $(P<0.05)$ for female weight, blood intake and blood-feeding. Non-parametric tests were applied for non-normal distributions and differences and data comparisons for oviposition, egg viability and viral susceptibility, which were assessed by the MannWhitney U-test $(P<0.05)$. Plots and analyses were performed using GraphPad Prism 5 software (GraphPad, La Jolla California, USA).

\section{Results}

\section{Insecticide resistance profile of the Aedes Rio population Insecticide bioassay}

The insecticide resistance profile of Aedes Rio larvae exposed to temephos and adults exposed to deltamethrin and malathion exposures were determined (Table 2, Fig. 2). Dose response bioassays indicated that Aedes Rio larvae presented moderate insecticide $\mathrm{RR}$ to temephos $\left(\mathrm{LC}_{50}=0.028 \mathrm{mg} / \mathrm{l} ; \mathrm{RR}_{50}=6.6\right)$. Aedes Rio female adult mosquitoes presented high insecticide $R R$ to deltamethrin $\left(\mathrm{LC}_{50}=32.25 \mathrm{mg} / \mathrm{m}^{2} ; \mathrm{RR}_{50}=33.1\right)$ but were susceptible to malathion $\left(\mathrm{LC}_{50}=0.207 \mathrm{~g} / \mathrm{m}^{2} ; \mathrm{RR}_{50}=1.4\right)$. When comparing the slopes, Aedes Rio presented greater heterogeneity than the Rockefeller strain (lower slope values).

\section{Enzymatic assay}

Since insecticide resistance is usually related to metabolic resistance, detoxification enzyme activities, involved with altered RR [41], were also assayed (Table 3, Additional file 1: Figure S1). In comparison to the Rockefeller strain, Aedes Rio males and females presented altered $\alpha$-EST activity $(H=67.54, d f=3, P<0.0001)$ and highly altered GST activity $(H=137.7, d f=3, \quad P<0.0001)$. Altered female and highly altered male $p$ NPA-EST activities were also observed $(H=66.33, d f=3, P<0.0001)$. No difference was observed for MFO activity, although Aedes Rio presented lower $\beta$-EST activities $(H=59.87, d f=3$, $P<0.0001$ ) (Additional file 1: Figure S1).

\section{Molecular assay}

Target site insensitivity due to mutation is another insecticide resistance mechanism found in several field populations. For this reason, the frequency of $k d r$ mutations at the 1016 and 1534 sites in the IIS6 and IIIS6 $\mathrm{AaNa}_{V}$ segments, respectively, were investigated in 38 males. The genotype frequencies did not deviate from the HardyWeinberg assumption $\left(X^{2}=1.73, P=0.3298\right)$, suggesting that the $k d r$ alleles reached an equilibrium in this strain and that the genotypes are not under any evident selection in laboratory conditions. The results analysed for both sites in linkage and as an individual locus [36] are provided in Table 4.

The alleles $\mathrm{Na}_{V} \mathrm{R} 1$ and $\mathrm{Na}_{\mathrm{V}} \mathrm{R} 2$ were present at high frequencies. The SS genotype was not detected and "resistant genotypes" were observed at a very high frequency (92.1\%).

\section{Fitness evaluation of Aedes Rio Adult lifespan}

No significant differences in male and female lifespans between both populations in cages under $10 \%$ sucrose ad libitum were observed (Fig. 3; male median survival (median \pm SEM): Rockefeller $(31 \pm 1.88$ days), Aedes Rio ( $36.5 \pm 2.25$ days), Mantel-Cox test $P=0.2088$; female median survival (median \pm SEM): Rockefeller ( $41 \pm 2.08$ days), Aedes Rio ( $37 \pm 1.83$ days), $P=0.061$ ). However, in the cages with blood-feeding offered on a weekly basis, Rockefeller males presented reduced survival in comparison to Aedes Rio males (median survival, in days (median \pm SEM): Rockefeller: $24 \pm 1.54$; Aedes Rio: $35 \pm 1.84, P<0.0001)$ and Rockefeller males from cages with $10 \%$ sucrose offered ad libitum $(P<0.0001)$. However, blood-fed Rockefeller females presented longer lifespans compared to Aedes Rio females (median survival, in days (median \pm SEM): Rockefeller: $70 \pm 3.07$; Aedes Rio: $53.5 \pm 2.16, P<0.0003)$. Females from both populations offered blood on a weekly basis also presented reduced

Table 2 Resistance profile of Aedes Rio mosquitoes to temephos, deltamethrin and malathion

\begin{tabular}{|c|c|c|c|c|c|c|c|c|}
\hline Insecticide & Population & $\mathrm{LC}_{50}$ & $95 \% \mathrm{Cl}^{2} \mathrm{C}_{50}$ & $\mathrm{LC}_{95}$ & $95 \% \mathrm{Cl}^{2} \mathrm{LC}_{95}$ & Slope & $\mathrm{RR}_{50}^{\mathrm{a}}$ & $\mathrm{RR}_{95}$ \\
\hline \multirow[t]{2}{*}{ Temephos } & Rockefeller & 0.0042 & $0.0026-0.0066$ & 0.0067 & $0.0041-0.011$ & 8.0 & 1.0 & 1.0 \\
\hline & Aedes Rio & 0.028 & $0.0206-0.038$ & 0.068 & $0.045-0.102$ & 4.3 & 6.6 & 10.1 \\
\hline \multirow[t]{2}{*}{ Deltamethrin } & Rockefeller & 0.974 & $0.59-1.61$ & 2.17 & $1.1466-4.09$ & 4.7 & 1.0 & 1.0 \\
\hline & Aedes Rio & 32.25 & $21.1-49.3$ & 100.9 & 53.60-189.93 & 3.3 & 33.1 & 46.6 \\
\hline \multirow[t]{2}{*}{ Malathion } & Rockefeller & 0.150 & $0.076-0.299$ & 0.34 & $0.207-0.564$ & 4.6 & 1.0 & 1.0 \\
\hline & Aedes Rio & 0.207 & $0.108-0.396$ & 0.48 & $0.199-1.17$ & 4.5 & 1.4 & 1.4 \\
\hline
\end{tabular}

${ }^{\mathrm{a}}$ Aedes Rio presenting $\mathrm{RR}_{50}<5$ were considered susceptible, $\mathrm{RR}_{50}$ between 5 and 10 were considered moderately resistant and $\mathrm{RR}_{50}>10$ were considered resistant Notes: lethal concentration (LC) values expressed as $\mathrm{mg} / \mathrm{l}, \mathrm{mg} / \mathrm{m}^{2}$ and g/m $\mathrm{m}^{2}$, respectively. Confidence intervals (Cl) of lethal concentrations, slope and resistance ratio (RR) 50 and 95 are also shown

Abbreviations: LC50, concentration that kills $50 \%$ of the animals; LC95, concentration that kills $95 \%$ of the animals 
mortality in comparison to sucrose-fed females (Rockefeller $P<0.0001$; Aedes Rio $P<0.0001)$.

\section{Weight and blood-feeding}

For estimates on the amount of blood taken, pools of insects before and after their blood meal were weighed.
The weight before the blood meal also served as an estimate for whole-body size. No significant difference in female mosquito weight (Fig. 4a; mean \pm SE: Rockefeller: $1.72 \pm 0.11 \mathrm{mg}$; Aedes Rio: $2.06 \pm 0.31 \mathrm{mg}$, ANOVA: $F=8.83 P=0.3325)$ and the total amount of ingested blood (Fig. 4b; mean \pm SE: Rockefeller: $2.07 \pm 0.23 \mathrm{mg}$;
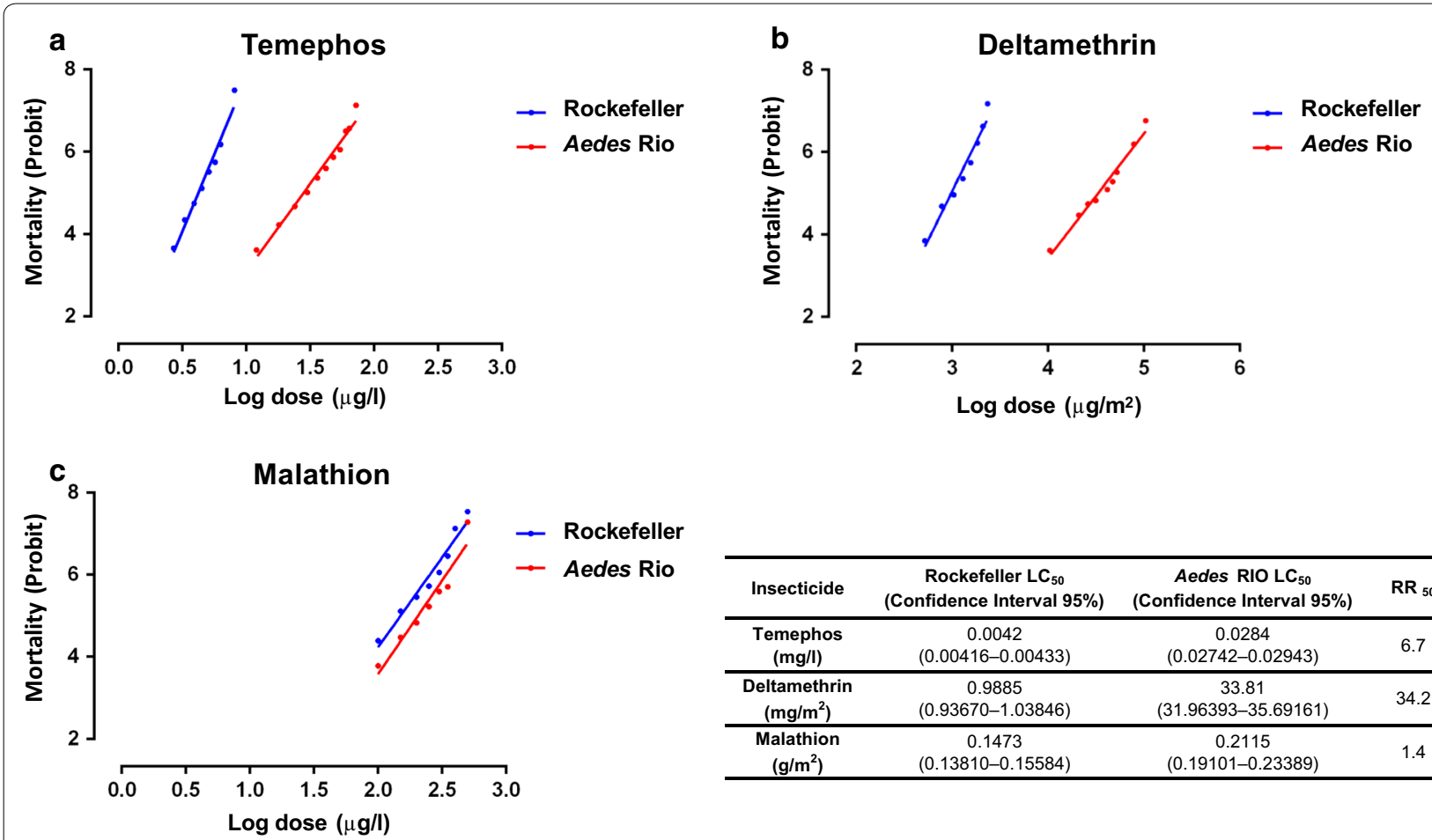

\begin{tabular}{cccc}
\hline Insecticide & $\begin{array}{c}\text { Rockefeller LC } \\
\text { (Confidence Interval 95\%) }\end{array}$ & $\begin{array}{c}\text { Aedes RIO LC } \\
\text { (Confidence Interval 95\%) }\end{array}$ & RR $_{\mathbf{5 0}}$ \\
\hline $\begin{array}{c}\text { Temephos } \\
(\mathbf{m g} / \mathbf{l})\end{array}$ & $\begin{array}{c}0.0042 \\
(0.00416-0.00433)\end{array}$ & $\begin{array}{c}0.0284 \\
(0.02742-0.02943)\end{array}$ & 6.7 \\
\hline $\begin{array}{c}\text { Deltamethrin } \\
\left(\mathbf{m g} / \mathbf{m}^{2}\right)\end{array}$ & $\begin{array}{c}0.9885 \\
(0.93670-1.03846)\end{array}$ & $\begin{array}{c}33.81 \\
(31.96393-35.69161)\end{array}$ & 34.2 \\
\hline $\begin{array}{c}\text { Malathion } \\
\left(\mathbf{g} / \mathbf{m}^{2}\right)\end{array}$ & $\begin{array}{c}0.1473 \\
(0.13810-0.15584)\end{array}$ & $\begin{array}{c}0.2115 \\
(0.19101-0.23389)\end{array}$ & 1.4 \\
\hline
\end{tabular}

Fig. 2 Linear regression for Aedes Rio mortality after exposure to temephos (a), deltamethrin (b) and malathion (c). Mosquitoes from the Rockefeller strain were used for comparison in all tests (blue lines)

Table 3 Enzyme activity alterations in Aedes RIO males and females compared to the Rockefeller strain

\begin{tabular}{lllllr}
\hline Aedes Rio & AChE & GST & a-EST & $\beta$-EST & MFO \\
\hline Male & 0 & 76 & 28 & 0 & 0 \\
Female & 10 & 50 & 16 & 0 & 28 \\
\hline
\end{tabular}

Notes: Enzyme activities were classified as unaltered (regular font), altered (italic) and highly altered (italic and bold), if $<15,15-50$ or $>50 \%$ of individuals, respectively, presented activities above the corresponding Rockefeller 99th percentile value (see "Methods" for more details)

Abbreviations: MFO, multi-function oxidases; EST, esterases; $\alpha$-EST, $\beta$-EST and $\rho$ NPA-EST, substrates ( $\alpha$ - and $\beta$-naphthyl and $\rho$-nitrophenil acetates) employed for EST, GST, glutathione S-transferase

Table 4 Allelic and genotypic frequencies of the Aedes Rio population for the alleles $\mathrm{Na}_{\mathrm{V}} \mathrm{S}$

\begin{tabular}{|c|c|c|c|c|c|c|c|c|c|c|}
\hline \multirow[t]{2}{*}{ Population } & \multicolumn{3}{|c|}{ Allelic frequency } & \multicolumn{6}{|c|}{ Genotypic frequency } & \multirow[t]{2}{*}{ "Resistant" genotypes } \\
\hline & $S$ & R1 & $\mathrm{R} 2$ & SS & SR1 & R1R1 & SR2 & R1R2 & R2R2 & \\
\hline Aedes Rio & 0.039 & 0.539 & 0.422 & 0 & 0.026 & 0.263 & 0.053 & 0.526 & 0.132 & 0.921 \\
\hline
\end{tabular}

${ }^{a} \mathrm{R} 1 \mathrm{R} 1+\mathrm{R} 1 \mathrm{R} 2+\mathrm{R} 2 \mathrm{R} 2$

Notes: $\mathrm{Na}_{\mathrm{V}} \mathrm{S}\left(1016 \mathrm{Val}^{+}+1534 \mathrm{Phe}^{+}\right), \mathrm{Na}_{\mathrm{V}} \mathrm{R} 1\left(1016 \mathrm{Val}^{+}+1534 \mathrm{Cys}^{\mathrm{kdr}}\right)$ and Na $\mathrm{R} 2\left(1016 \mathrm{ll}^{\mathrm{kdr}}+1534 \mathrm{Cys}^{\mathrm{kdr}}\right)$ 


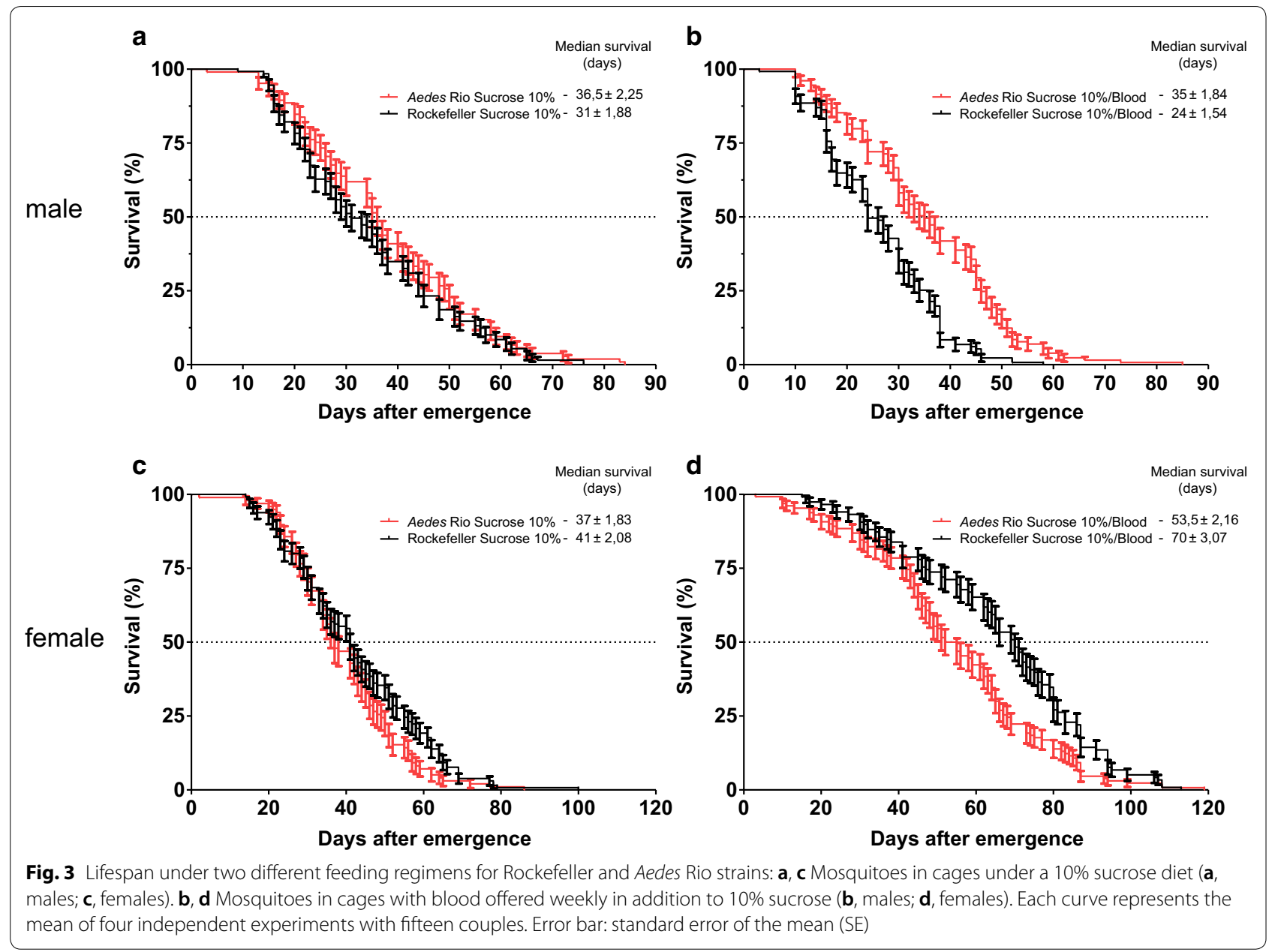

Aedes Rio $=1.93 \pm 0.18 \mathrm{mg}$, ANOVA: $F=1.64 P=0.6461$ ) were observed between the Rockefeller strain and the Aedes Rio population.

No difference between the two populations concerning the total number of blood-fed females was observed (Fig. 4c; mean \pm SE: Rockefeller: $94.8 \pm 4.0 \%$; Aedes Rio: $68.8 \pm 9.8 \%$, Mann Whitney test $U=1.0, Z=2.19$, $P=0.057)$.

\section{Female fertility}

The total number of eggs/female and the rate of egg hatching are shown in Fig. 5. A comparison between populations revealed no difference in the total number of laid eggs (Fig. 5a; mean \pm SE: Rockefeller: $105.1 \pm 2.72$; Aedes Rio: $107.8 \pm 3.49$, Mann Whitney test $U=6466, Z=1.37$, $P=0.1723)$. However, the Aedes Rio population showed lower egg viability in comparison to the Rockefeller strain (Fig. 5b; mean \pm SE: Rockefeller: $77.79 \pm 1.4 \%$; Aedes Rio: $58.57 \pm 1.77 \%$, Mann Whitney test $U=2884, Z=7.45$, $P<0.0001)$.

\section{Virus susceptibility}

Susceptibility to Zika infection in mosquitoes artificially fed viremic blood meals was assessed (Fig. 6). The Aedes Rio population showed similar Zika viral loads and infection rates (mean \pm SE: $4.53 \times 10^{4} \pm 1.14 \times 10^{4} \mathrm{PFU}$; IR: $100 \%)$ compared to the Rockefeller strain (mean \pm SE: $2.02 \times 10^{4} \pm 0.71 \times 10^{4}$ PFU; IR: $100 \%$, Mann Whitney test $U=176, Z=0.25, P=0.3929)$.

\section{Discussion}

Distinct field mosquito populations may diverge from laboratory-reared mosquitoes in regard to the overall fitness, especially when they possess a distinct profile for resistance to insecticides, as vastly documented [26, 27]. Still, even when similar phenotypes are observed between field and laboratory strains, these similarities may have different genetic sources. For example, the comparison between profiles of field insecticide-resistant mosquitoes and organophosphate-selected laboratory strains presented a similar temephos resistance ratio. However molecular analysis revealed different detoxification 

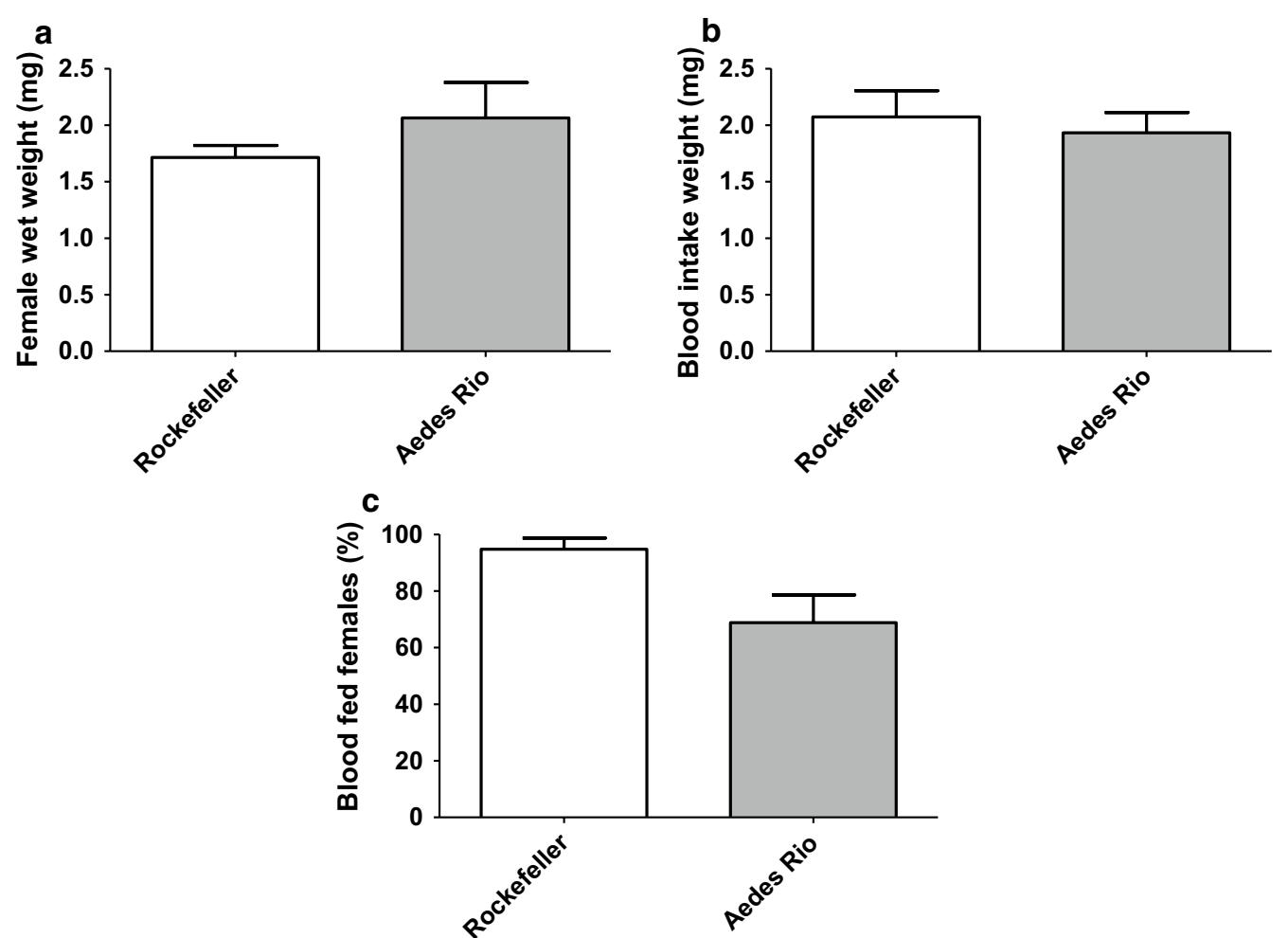

Fig. 4 Female weight and blood-feeding for the Rockefeller strain and the Aedes Rio population. Female weight (a), ingested blood weight (b), percentage of blood-fed females (c). Data represent the means of four independent experiments, each consisting in four pools containing 10 females. Blood weight was obtained by subtraction of the weight of unfed from the weight of blood-fed female pools. Error bar: standard error of the mean (SE)
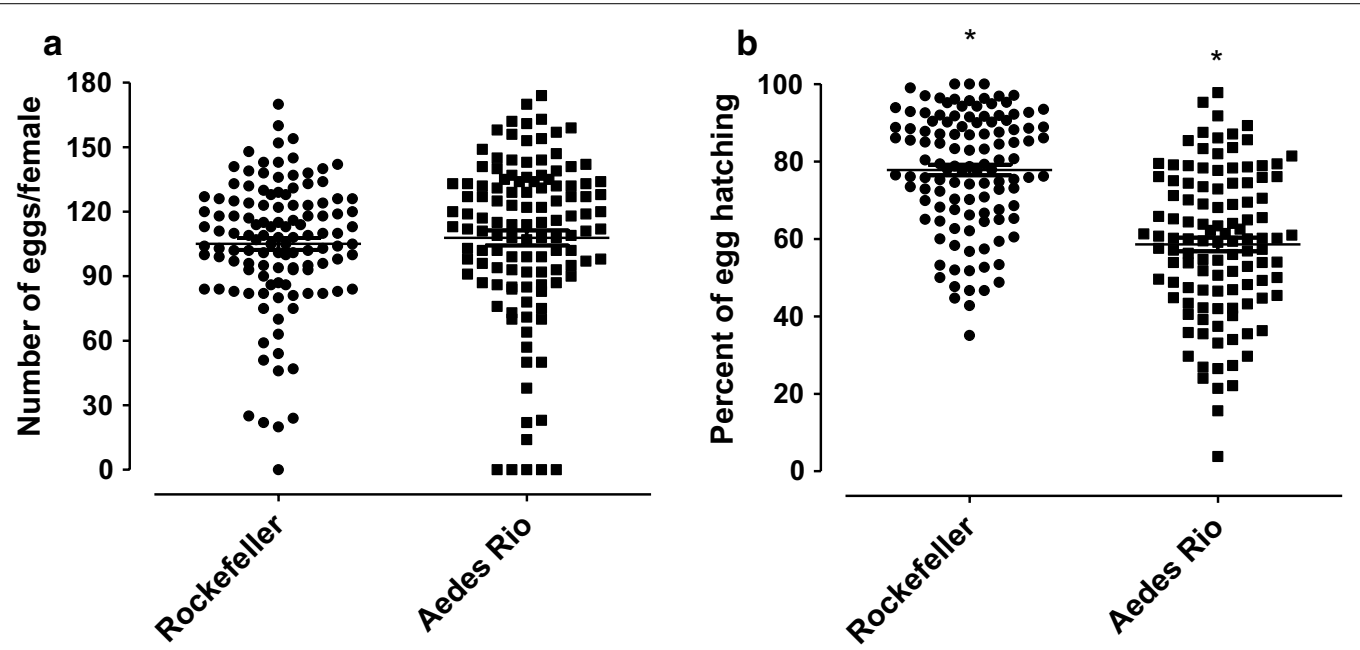

Fig. 5 Oviposition and egg viability comparison between the Rockefeller strain and the Aedes Rio population. a Number of eggs per female. $\mathbf{b}$ Egg viability. Data represent three independent experiments, each consisting of 40 females. Each dot indicates the number of eggs or egg viability from an individual female. Error bar: SE 


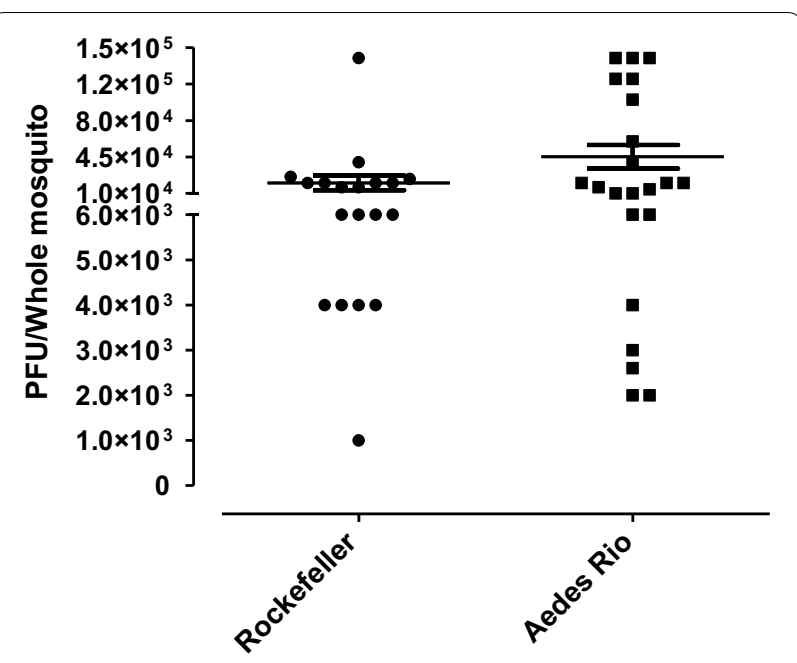

Fig. 6 Mosquito viral susceptibility. Females were fed viremic blood containing $10^{7} \mathrm{PFU} / \mathrm{ml}$ of the Zika virus, and the number of PFU was determined in whole mosquitoes (viral load) at seven days post-infection. Error bar: SE

enzyme patterns with the presence of different classes of enzymes responsible for insecticide resistance between populations, revealing that the ecosystem may select different detoxification mechanisms [25]. Therefore, careful fitness evaluations concerning Ae. aegypti mosquitoes with a similar genetic profile to field populations may result in relevant information for vector control policies, such as the selection of a suitable insecticide class or other strategies, since fitness aspects of natural populations may cause diversified responses in comparison to those observed in a reference laboratory strain.

Aedes Rio insecticide resistance was observed against temephos and deltamethrin, but not malathion. To date, no mutations in the acetylcholinesterase gene (ace1) leading to organophosphate resistance have been described in Ae. aegypti. In this way, resistance to this insecticide is mainly due to metabolic changes. This type of resistance may be diverse in the different mosquito life stages (temephos-larvicide; malathion-adulticide) which may impair cross-resistance mechanisms and stagerelated overall fitness, since these enzymes also play a role in physiological functions. The extensive use of insecticides in vector control in several Brazilian states has led to increased mosquito resistance to temephos and deltamethrin. Indeed, some studies have reported increasing Aedes resistance to the organophosphate temephos and pyrethroids in Brazil recently, especially in coastal areas [36, 42-44]. Studies evaluating Ae. aegypti populations from Rio de Janeiro have reported high insecticide resistance in several regions [33, 36, 40, 45-48]. Therefore, the insecticide resistance profile observed herein in Aedes
Rio must have been inherited from the field populations used for interbreeding.

Usually, high insecticide RR levels are associated with metabolic changes such as higher expression or enhanced efficiency of detoxification enzymes [41, 49]. These enzymes display a broad substrate spectrum with variable affinities and are, therefore, able to detoxify a wide range of insecticide classes [43]. In the present study, no difference was observed for AChE activity in Aedes Rio when compared to the Rockefeller strain. However, metabolic detoxification changes were noted, mainly, for GST, $\alpha$-EST and $p$ NPA-EST, which showed higher enzyme activities, but not $\beta$-EST. These enzymes have previously been noted as exhibiting enhanced activity after organophosphate selection and are associated with organophosphate resistance [25, 33, 46, 50-54]. Diniz et al. [25] observed higher GST and esterase activities in a Brazilian laboratory strain under temephos selection, similar to field populations. Similar results were reported by Bellinato et al. [43] when evaluating several Brazilian Ae. aegypti populations showing higher esterase and GST activities than MFO enzymes.

Several studies have correlated MFO activity or expression levels of the P450 cyp family genes to increased pyrethroid resistance; however, so far there is no particular marker available for large-scale analysis [55-58]. On the other hand, genotyping of specific $k d r$ mutations has also been well correlated to pyrethroid resistance, and are thus currently widely used in molecular surveillance of insecticide resistance [28, 59-64]. No altered MFO concentrations were observed herein. However, a high frequency of "resistant" $k d r$ genotypes (92.1\%) was noted, suggesting that deltamethrin resistance is primary due to target site alteration and not to metabolic mechanisms. In Ae. aegypti, two mutations in the V1016G/I site and one in F1534C site have been observed in several resistant field populations worldwide [65-67]. Reports on Brazilian Ae. aegypti populations indicate a high frequency of both V1016I and F1534C substitutions in comparison to susceptible alleles $[36,40,64,68,69]$. Thus, the enzymatic activity variations and $k d r$ mutations observed in Aedes Rio were inherited characteristics from the mosquito populations collected from Rio de Janeiro and used for interbreeding, leading to the enhanced RR observed herein.

The impact of insecticide resistance on the overall fitness of mosquitoes under an environment free of insecticides is a known phenomenon, and involves several negative effects on development and reproduction [25, $26,35,62,70,71]$. This is of epidemiological relevance since resistance tends to be lost along generations in the absence of insecticide selection. Therefore, in addition to understanding the status of susceptibility to the 
current method employed against a target vector, it is also desirable to unravel which alterations might have been selected in its life table. In this study, we did not observe lifespan differences between males of both Rockefeller and Rio strains from cages with a constant source of sucrose. Notwithstanding, Rockefeller males maintained in cages with blood offered on a weekly basis had lower survival rates compared to Rockefeller and Aedes Rio males kept in cages under a sucrose diet only. This may be related to the experimental design in which the sucrose-soaked cotton is withdrawn from the cage, leading to mosquito fasting which in turn results in greater female blood-feeding rates. Rockefeller males did not survive as long as Aedes Rio males when deprived from the sugar source. We hypothesize that although reared in parallel under the same laboratory conditions, these strains should have either acquired distinct nutrition reserves during the development or metabolized them differently. Accordingly, field-collected Anopheles gambiae males had a higher total lipid content than male mosquitoes of a laboratory strain reared under insectary feeding and optimum density conditions, which may be associated with differences in nutritional reserves and, therefore, fasting tolerance [72]. This higher tolerance for fasting periods in field mosquitoes is likely to be a consequence of distinct physiological traits between field and laboratory reference strains, which maintain field mosquitoes under more adverse conditions.

Rockefeller females showed higher survival rates under blood-feeding conditions compared to Aedes Rio females. Lifespan reports comparing Ae. aegypti laboratory strains and field populations are diverse. Some studies indicate similar longevity for field and laboratory mosquitoes [26, 70]. Other studies report reduced lifespans of field mosquitoes, usually due to high insecticide resistance ratios $[19,71]$. For example, a Culex pipiens population resistant to organophosphates, likely due to increased esterase activity, had low survival rates [73]. Moreover, when resistance to temephos decreased in an Ae. aegypti field population, its longevity inversely increased [25]. In the present study, the lower survival rate of Aedes Rio females is probably one of the pleiotropic effects of mechanisms selected for resistance to insecticides, which may result in a high fitness cost under an environment free of insecticide, such as standard laboratory conditions.

Weekly blood-feeding led to increased female lifespan in both Rockefeller and Aedes Rio strains. Although it would be expected that blood-feeding would reduce the lifespan due to an increase in reactive oxygen species production and immune challenges [74-76], it is well documented that blood-feeding increases mosquito survival $[35,77-82]$. A longer lifespan in blood-fed females as observed herein, may be related to a richer nutritional composition. A longer lifespan is beneficial for vector competence, since female mosquitoes have time for multiple blood-feedings and therefore an increased chance to become infected and transmit arboviruses and pathogens.

Blood meals are an important parameter, since they are related to vectorial capacity through parasite ingestion and the number of deposited eggs [26, 71]. Thus, compared to the Rockefeller strain, Aedes Rio showed no difference in the amount of blood ingested. Accordingly, previous studies observed that field populations resistant to insecticides, also did not show difference in the amount of ingested blood compared with reference strains [28]. The number of females that accepted a blood source offered in the laboratory was lower in insecticideresistant field populations [23, 26]. This could be related to pleiotropic effects of mechanisms selected for resistance, or due to the laboratory conditions of blood-feeding to which the reference colonies are better adapted.

As the amount of blood ingested did not differ between the Rockefeller and Rio strains, the total number of oviposited eggs was similar between them. On the other hand, the fertility (rate of egg hatching) in Aedes Rio was lower than in Aedes Rockefeller. There are several examples evidencing the relationship between insecticide resistance status and reduced egg viability, as in Ae. aegypti populations resistant to permethrin [83] and temephos [25]. In contrast, several other studies have reported no difference in the viability of eggs from insecticide resistant populations [26, 35, 71]. This reinforces that diversified mechanisms selected for resistance in conjunction with the whole genetic background will determine the extension of interreference that those mechanisms will play in the overall insect phenotype.

In relation to vector competence, reports on Ae. aegypti susceptibility to the Zika virus are diverse, with varying viral loads and infection rates in this species [84-86]. In our study, Aedes Rio showed higher infection rates (8590\%) when compared to other field mosquitoes [87, 88]. For instance, laboratory infection rates varied between $40 \%$ in Ae. aegypti from Fernando de Noronha, PE, Brazil [85] and $60-80 \%$ in mosquito populations from Mexican cities [89]. These differences can be related to diverse factors, such as virus titre, virus strain and the mosquito genetic background [85, 87, 89-91].

\section{Conclusions}

Altogether, the present study revealed that Aedes Rio, a laboratory interbred strain of Ae. aegypti, originating from field mosquito populations collected from Rio de Janeiro, is resistant to the insecticides temephos 
and deltamethrin. Metabolic and target site resistance mechanisms selected in the original populations may be responsible for pleiotropic effects that caused a fitness cost in an environment free of insecticides, when compared to the laboratory reference strain Rockefeller. This decreased fitness however did not result in avoiding Zika virus infection and dissemination in the $A e$. aegypti Rio strain. We suggest that vector control programmes should consider adopting a recently established colony originating from the targeted population, in addition to a commonly employed laboratory reference strain. As observed here, diverse field-selected aspects, such as insecticide resistance, may significantly interfere with development and reproduction traits, which would potentially lead to uncertain conclusions when testing chemicals or new vector control strategies.

\section{Supplementary information}

Supplementary information accompanies this paper at https://doi. org/10.1186/s13071-020-04166-3.

Additional file 1: Figure S1. Detoxification enzyme activity of oneday-old mosquitoes from the Rockefeller strain and the Aedes Rio F4 population. Symbols represent significant differences between the same gender by a non-parametric One-way ANOVA test (Kruskal-Wallis) with Dunn's post-hoc test $(P=0.05 \%)$. The data represent two independent experiments totalling 50 mosquitoes for each condition. Mean deviation: SE. Statistical difference between populations $(P<0.05)$.

\section{Abbreviations}

$A a a_{v}$ : voltage-gated sodium channel gene; ace-1: acetylcholinesterase gene; AChE: acetylcholinesterase; BOD: biological oxygen demand incubator; BSL: biosafety level; Cys: cysteine; EST: esterase; GST: glutathione S-transferase; Ile: isoleucine; IR: infection rate; kdr: knockdown resistance gene; LC: lethal concentration; MFO: mixed function oxidases; PFU: plaque-forming units; Phe: phenylalanine; SE: standard error of the mean; SEM: standard error of the median; Val: valine; ZIKV: Zika virus.

\section{Acknowledgements}

The authors would like to dedicate the present work to Professor Mario Alberto Silva Neto (in memoriam) for all his support during the execution of this study. We thank Diogo Fernandes Bellinato for his skilful assistance.

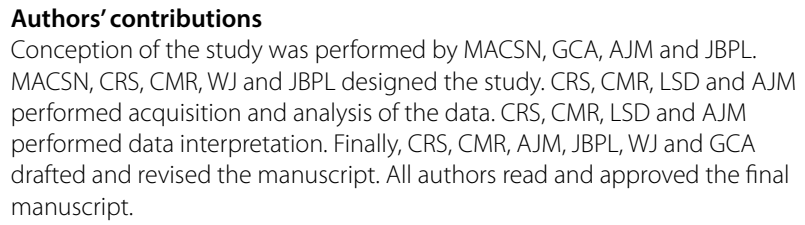

\section{Funding}

This study was funded by FAPERJ-ZIKA (210.896/2014) and partially supported by a post-doctoral scholarship from NIH UOR, FAPERJ-Zika and Coordenação de Aperfeiçoamento de Pessoal de Nível Superior (Capes) to CRS.

\section{Availability of data and materials}

All data generated or analysed during this study are included in this published article and its additional file.

\section{Ethics approval and consent to participate}

Guinea pigs used for mosquito feeding and assays were conducted under the approval of the Fundação Oswaldo Cruz Animal Use Ethics Committee (CEUA Fiocruz) LW-20/14.

\section{Consent for publication}

Not applicable.

\section{Competing interests}

The authors declare that they have no competing interests.

\section{Author details}

${ }^{1}$ Laboratório de Sinalização Celular Programa de Biologia Molecular e Biotecnologia, Instituto de Bioquímica Médica Leopoldo de Meis, Universidade Federal do Rio de Janeiro, Rio de Janeiro, RJ, Brazil. ${ }^{2}$ Laboratório de Fisiologia e Controle de Artrópodes Vetores, Instituto Oswaldo Cruz, Fiocruz, Rio de Janeiro, RJ, Brazil. ${ }^{3}$ Laboratório de Entomologia, Instituto de Biologia do Exército, Rio de Janeiro, RJ, Brazil. ${ }^{4}$ Laboratório de Bioquímica de Lipídios e Lipoproteínas, Programa de Biologia Molecular e Biotecnologia, Instituto de Bioquímica Médica Leopoldo de Meis, Universidade Federal do Rio de Janeiro, Rio de Janeiro, RJ, Brazil.

Received: 12 December 2019 Accepted: 2 June 2020

Published online: 08 June 2020

\section{References}

1. Maciel-De-Freitas R, Marques WA, Peres RC, Cunha SP, de Oliveira RL. Variation in Aedes aegypti (Diptera: Culicidae) container productivity in a slum and a suburban district of Rio de Janeiro during dry and wet seasons. Mem Inst Oswaldo Cruz. 2007;102:489-96.

2. Clemons A, Haugen M, Flannery E, Tomchaney M, Kast K, Jacowski C, et al. Aedes aegypti: an emerging model for vector mosquito development. Cold Spring Harb Protoc. 2010;2010:pdb.emo14.

3. Kraemer MG, Sinka ME, Duda KA, Mylne AQ, Shearer FM, Barker CM, et al. The global distribution of the arbovirus vectors Aedes aegypti and Ae. albopictus. elife. 2015;4:e08347.

4. Ramos-Castañeda J, Santos FB, Martínez-Veja R, Araujo JMG, Joint G, Sarti E. Dengue in Latin America: systematic review of molecular epidemiological trends. PLoS Negl Trop Dis. 2017;11:e0005224.

5. Whitehead SS, Blaney JE, Durbin AP, Murphy BR. Prospects for a dengue virus vaccine. Nat Rev Microbiol. 2007;5:518-28.

6. Nunes RD, Ventura-Martins G, Moretti DM, Medeiros-Castro P, RochaSantos C, Daumas-Filho CR, et al. Polyphenol-rich diets exacerbate AMPK-mediated autophagy, decreasing proliferation of mosquito midgut microbiota, and extending vector lifespan. PLoS Negl Trop Dis. 2016;10:e0005034.

7. Corbel V, Durot C, Achee NL, Chandre F, Coulibaly MB, David JP, et al. Second WIN International Conference on "Integrated approaches and innovative tools for combating insecticide resistance in vectors of arboviruses", October 2018, Singapore. Parasites Vectors. 2019;12:331.

8. Serrato IM, Caicedo PA, Orobio Y, Lowenberger C, Ocampo CB. Vector competence and innate immune responses to dengue virus infection in selected laboratory and field-collected Stegomyia aegypti (= Aedes aegypti). Med Vet Entomol. 2017;31:312-9.

9. Taracena ML, Bottino-Rojas V, Talyuli OAC, Walter-Nuno AB, Oliveira $J \mathrm{HM}$, Angleró-Rodriguez YI, et al. Regulation of midgut cell proliferation impacts Aedes aegypti susceptibility to dengue virus. PLoS Negl Trop Dis. 2018;5:e0006498.

10. Gloria-Soria A, Soghigian J, Kellner D, Powell JR. Genetic diversity of laboratory strains and implications for research: the case of Aedes aegypti. PLoS Negl Trop Dis. 2019;12:e0007930.

11. Briscoe DA, Malpica JM, Robertson A, Smith GJ, Frankham R, Banks RG, et al. Rapid loss of genetic variation in large captive populations of Drosophila flies: implications for the genetic management of captive populations. Conserv Biol. 1992;6:416-25.

12. Mukhopadhyay J, Rangel EF, Ghosh K, Munstermann LE. Patterns of genetic variability in colonized strains of Lutzomyia longipalpis (Diptera: Psychodidae) and its concequences. Am J Trop Med Hyg. 1997;57:216-21. 
13. Norris DE, Shurtleff AC, Toure YT, Lanzaro GC. Microsatellite DNA polymorphism and heterozygosity among field and laboratory populations of Anopheles gambiae s.s. (Diptera: Culicidae). J Med Entomol. 2001;38:336-40.

14. Reisen WK. Lessons from the past: historical studies by the University of Maryland and the University of California. In: Scott TW, Takken W, editors. Ecological aspects for application of genetically modified mosquitoes. Berkeley-Dordrecht: Kluwer Academic; 2004. p. 25-32.

15. Kristensen TN, Sorensen AC. Inbreeding-lessons from animal breeding, evolutionary biology and conservation genetics. Anim Sci. 2005;80:121-33.

16. Benedict MQ, Knols BG, Bossin HC, Howell PI, Mialhe E, Caceres C, et al. Colonisation and mass rearing: learning from others. Malar $\mathrm{J}$. 2009;8(Suppl. 2):S4.

17. Howell PI, Knols BGJ. Male mating biology. Malar J. 2009;8(Suppl. 2):S8.

18. Ffrench-Constant RH. The molecular genetics of insecticide resistance. Genetics. 2013;194:807-15.

19. Laurenti MD, da Matta VL, Pernichelli T, Secundino NF, Pinto LC, Corbett $C E$, et al. Effects of salivary gland homogenate from wild-caught and laboratory-reared Lutzomyia longipalpis on the evolution and immunomodulation of Leishmania (Leishmania) amazonensis infection. Scand J Immunol. 2009;70:389-95.

20. Ben Hadj Ahmed S, Kaabi B, Chelbi I, Cherni S, Derbali M, Laouini D, Zhioua E. Colonization of Phlebotomus papatasi changes the effect of pre-immunization with saliva from lack of protection towards protection against experimental challenge with Leishmania major and saliva. Parasites Vectors. 2011:4:126.

21. Munstermann LE. Unexpected genetic consequences of colonization and inbreeding: allozyme tracking in Culicidae (Diptera). Ann Entomol Soc Am. 1994;87:157-64.

22. Cornet $\mathrm{S}$, Gandon $\mathrm{S}$, Rivero A. Patterns of phenoloxidase activity in insecticide resistant and susceptible mosquitoes differ between laboratoryselected and wild-caught individuals. Parasites Vectors. 2013;6:315.

23. Belinato TA, Valle $D$. The impact of selection with diflubenzuron, a chitin synthesis inhibitor, on the fitness of two Brazilian Aedes aegypti field populations. PLoS ONE. 2015;10:e0130719.

24. Abedi ZH, Brown AWA. DDT-resistance hazard in North American populations of Aedes aegypti. Mosq News. 1961;21:1-4.

25. Diniz DFA, de Melo-Santos MA, Santos EM, Beserra EB, Helvecio E, de Carvalho-Leandro D, et al. Fitness cost in field and laboratory Aedes aegypti populations associated with resistance to the insecticide temephos. Parasites Vectors. 2015;8:662

26. Belinato TA, Martins AJ, Valle D. Fitness evaluation of two Brazilian Aedes aegypti field populations with distinct levels of resistance to the organophosphate temephos. Mem Inst Oswaldo Cruz. 2012;107:916-22.

27. Gonçalves CM, Melo FF, Bezerra JM, Chaves BA, Silva BM, Silva LD, et al. Distinct variation in vector competence among nine field populations of Aedes aegypti from a Brazilian dengue-endemic risk city. Parasites Vectors. 2014;7:320.

28. Martins AJ, Ribeiro CDM, Bellinato DF, Peixoto AA, Valle D, Lima JBP. Effect of insecticide resistance on development, longevity and reproduction of field or laboratory selected Aedes aegypti populations. PLOS ONE. 2012;7:e31889.

29. WHO. Instructions for determining the susceptibility or resistance of mosquito larvae to insecticides. Report of the WHO Expert Committee on resistance of vectors and reservoirs of diseases to pesticides. Geneva: World Health Organization; 1981.

30. WHO. Monitoring and managing insecticide resistance in Aedes mosquito populations Interim guidance for entomologists. Geneva: World Health Organization; 2016

31. Valle D, Montella IR, Viana-Medeiros PF, Ribeiro RA, Martins AJ, Lima JBP. Quantification metodology for enzyme activity related to insecticide resistance in Aedes aegypti. Brasília: Ministério da Saúde/Brasil; 2006.

32. Viana-Medeiros PF, Bellinato DF, Martins AJ, Valle D. Insecticide resistance, associated mechanisms and fitness aspects in two Brazilian Stegomyia aegypti (= Aedes aegypti) populations. Med Vet Entomol. 2017;31:340-50.

33. Montella IR, Martins AJ, Viana-Medeiros PF, Lima JBP, Braga IA, Valle D. Insecticide resistance mechanisms of Brazilian Aedes aegypti populations from 2001 to 2004. Am J Trop Med Hyg. 2007;77:467-77.
34. Martins I Jr., Solomon SE, Mikheyev AS, Mueller UG, Ortiz A, Bacci M Jr. Nuclear mitochondrial-like sequences in ants: evidence from Atta cephalotes (Formicidae: Attini). Insect Mol Biol. 2007;16:777-84.

35. Brito LP, Linss JG, Lima-Camara TN, Belinato TA, Peixoto AA, Lima JB, et al. Assessing the effects of Aedes aegypti Kdr mutations on pyrethroid resistance and its fitness cost. PLOS ONE. 2013;8:e60878.

36. Linss JG, Brito LP, Garcia GA, Araki AS, Bruno RV, Lima JB, et al. Distribution and dissemination of the Val1016lle and Phe1534Cys Kdr mutations in Aedes aegypti Brazilian natural populations. Parasites Vectors. 2014;7:25.

37. Shorrocks B. The genesis of diversity. London: Hodder and Stoughton; 1978.

38. Cheng YL, Lin YS, Chen CL, Tsai TT, Tsai CC, Wu YW, et al. Activation of $\mathrm{Nrf} 2$ by the dengue virus causes an increase in CLEC5A, which enhances TNF-a production by mononuclear phagocytes. Sci Rep. 2016;6:32000.

39. Raymond M. Presentation d'une programme d'analyse logprobit pour microordinateur. Cah ORSTOM Sér Ent Med Parasitol. 1985;22:117-21.

40. Brito LP, Carrara L, de Freitas RM, Lima JBP, Martins AJ. Levels of resistance to pyrethroid among distinct $k d r$ alleles in Aedes aegypti laboratory lines and frequency of $k d r$ alleles in 27 natural populations from Rio de Janeiro, Brazil. Biomed Res Int. 2018;2018:2410819.

41. Hemingway J, Hawkes N, Mccarroll L, Ranson H. The molecular basis of insecticide resistance in mosquitoes. Insect Biochem Mol Biol. 2004;34:653-65.

42. Macoris MLG, Camargo MF, Silva IG, Takaku L, Andrighetti MTM. Modificação da susceptibilidade de Aedes (Stegomyia) aegypti ao temefós. Rev Pat Trop. 1995;24:31-40.

43. Bellinato DF, Viana-Medeiros PF, Araújo SC, Martins AJ, Lima JBP, Valle D. Resistance status to the insecticides temephos, deltamethrin, and diflubenzuron in Brazilian Aedes aegypti populations. Biomed Res Int. 2016;2016:8603263.

44. Chediak M, Pimenta FG Jr, Coelho GE, Braga IA, Lima JBP, Cavalcante KRLJ, et al. Spatial and temporal country-wide survey of temephos resistance in Brazilian populations of Aedes aegypti. Mem Inst Oswaldo Cruz. 2016;111:311-21.

45. Lima JBP, da-Cunha MP, da Silva RC, Galardo AK, Soares SS, Braga IA, et al. Resistance of Aedes aegypti to organophosphates in several municipalities in the state of Rio de Janeiro and Espírito Santo, Brazil. Am J Trop Med Hyg. 2003;68:329-33.

46. Braga IA, Mello CB, Montella IR, Lima JB, Martins Ade J, Medeiros PF, Valle D. Effectiveness of methoprene, an insect growth regulator, against temephos-resistant Aedes aegypti populations from different Brazilian localities, under laboratory conditions. J Med Entomol. 2005;42:830-7.

47. da-Cunh MP, Lima JBP, Brogdon WG, Moya GE, Valle D. Monitoring of resistance to the pyrethroid cypermethrin in Brazilian Aedes aegypti (Diptera: Culicidae) populations collected between 2001 and 2003. Mem Inst Oswaldo Cruz. 2005;100:441-4.

48. Bona ACD, Chitolina RF, Fermino ML, de Castro Poncio L, Weiss A, Lima JB, et al. Larval application of sodium channel homologous dsRNA restores pyrethroid insecticide susceptibility in a resistant adult mosquito population. Parasites Vectors. 2016;9:397.

49. Braga IA, Valle D. Aedes aegypti: inseticidas, mecanismos de ação e resistência. Epidemiol Serv Saúde. 2007;16:279-93.

50. Li X, Schuler MA, Berenbaum MR. Molecular mechanisms of metabolic resistance to synthetic and natural xenobiotics. Annu Rev Entomol. 2007:52:231-53.

51. Melo-Santos MAV, Varjal-Melo JJ, Araújo AP, Gomes TC, Paiva MH, Regis $L N$, et al. Resistance to the organophosphate temephos: mechanisms, evolution and reversion in an Aedes aegypti laboratory strain from Brazil. Acta Trop. 2010;113:180-9.

52. Lumjuan N, Rajatileka S, Changsom D, Wicheer J, Leelapat P, Prapanthadara $L A$, et al. The role of the Aedes aegypti Epsilon glutathione transferases in conferring resistance to DDT and pyrethroid insecticides. Insect Biochem Mol Biol. 2011;41:203-9.

53. Reddy BPN, Rao BP, Prasad GBKS, Raghavendra K. Identification and classification of detoxification enzymes from Culex quinquefasciatus (Diptera: (ulicidae). Bioinformation. 2012;8:430-6.

54. Saavedra-Rodriguez K, Strode C, Flores AE, Garcia-Luna S, Reyes-Solis G, Ranson $\mathrm{H}$, et al. Differential transcription profiles in Aedes aegypti detoxification genes after temephos selection. Insect Mol Biol. 2014;23:199-215. 
55. Strode C, Wondji CS, David JP, Hawkes NJ, Lumjuan N, Nelson DR, et al. Genomic analysis of detoxification genes in the mosquito Aedes aegypti. Insect Biochem Mol Biol. 2008;38:113-23.

56. Poupardin R, Riaz MA, Vontas J, David JP, Reynaud S. Transcription profiling of eleven cytochrome P450s potentially involved in xenobiotic metabolism in the mosquito Aedes aegypti. Insect Mol Biol. 2010;19:185-93.

57. Marcombe S, Mathieu RB, Pocquet N, Riaz MA, Poupardin R, Sélior S, et al. Insecticide resistance in the dengue vector Aedes aegypti from Martinique: distribution, mechanisms and relations with environmental factors. PLoS ONE. 2012;7:e30989.

58. Faucon F, Dusfour I, Gaude T, Navratil V, Boyer F, Chandre F, et al. Identifying genomic changes associated with insecticide resistance in the dengue mosquito Aedes aegypti by deep targeted sequencing. Genome Res. 2015;25:1347-59.

59. Martinez-Torres D, Chandre F, Williamson MS, Darriet F, Bergé JB, Devonshire AL, et al. Molecular characterization of pyrethroid knockdown resistance $(k d r)$ in the major malaria vector Anopheles gambiae s.s. Insect Mol Biol. 1998;7:179-84.

60. Rinkevich F, Du Y, Dong K. Diversity and convergence of sodium channel mutations involved in resistance to pyrethroids. Pestic Biochem Physiol. 2013;106:93-100.

61. Platt N, Kwiatkowska RM, Irving H, Diabaté A, Dabire R, Wondji CS. Targetsite resistance mutations ( $k d r$ and $R D L$ ), but not metabolic resistance, negatively impact male mating competiveness in the malaria vector Anopheles gambiae. Heredity. 2015;115:243-52.

62. Belinato TA, Martins AJ. Insecticide resistance and fitness cost. In: Trdan S, editor. Insecticides resistance. London: IntechOpen; 2016. p. 233-61.

63. Donnelly M, Isaacs A, Weetman D. Identification, validation, and application of molecular diagnostics for insecticide resistance in malaria vectors. Trends Parasitol. 2016:32:197-206.

64. Aguirre-Obando OA, Martins AJ, Navarro-Silva MA. First report of the Phe1534Cys Kdr mutation in natural populations of Aedes albopictus from Brazil. Parasites Vectors. 2017;10:160.

65. Saavedra-Rodriguez K, Urdaneta-Marquez L, Rajatileka S, Moulton M, Flores $A E$, Fernandez-Salas I, et al. A mutation in the voltage-gated sodium channel gene associated with pyrethroid resistance in Latin American Aedes aegypti. Insect Mol Biol. 2007;16:785-98.

66. Yanola J, Somboon P, Walton C, Nachaiwieng W, Somwang P, Prapanthadara L. High-throughput assays for detection of the F1534C mutation in the voltage-gated sodium channel gene in permethrin-resistant Aedes aegypti and the distribution of this mutation throughout Thailand. Trop Med Int Health. 2011;16:501-9.

67. Moyes CL, Vontas J, Martins AJ, Ng LC, Koou SY, Dusfour I, et al. Contemporary status of insecticide resistance in the major Aedes vectors of arboviruses infecting humans. PLoS Negl Trop Dis. 2017;11:e0005625.

68. Martins AJ, Lima JB, Peixoto AA, Valle D. Frequency of Val1016lle mutation in the voltage-gated sodium channel gene of Aedes aegypti Brazilian populations. Trop Med Int Health. 2009;14:1351-5.

69. Chapadense FG, Fernandes EKK, Lima JBP, Martins AJ, Silva LC, Rocha WT, et al. Phenotypic and genotypic profile of pyrethroid resistance in populations of the mosquito Aedes aegypti from Goiânia, Central West Brazil. Rev Soc Bras Med Trop. 2015:48:607-9.

70. Jaramillo-O N, Fonseca-González I, Chaverra-Rodríguez D. Geometric morphometrics of nine field isolates of Aedes aegypti with different resistance levels to lambda-cyhalothrin and relative fitness of one artificially selected for resistance. PLoS ONE. 2014;9:e96379.

71. Martins AJ, Valle D. The pyrethroid knockdown resistance. In: Soloneski S, Larramendy M, editors. Insecticides-basic and other applications. London: IntechOpen; 2001. p. 17-38.

72. Huho BJ, Ng'habi KR, Killeen GF, Nkwengulila G, Knols BGJ, Ferguson HM. Nature beats nurture: a case study of the physiological fitness of free-living and laboratory-reared male Anopheles gambiae s.l. J Exp Biol. 2007:210:2939-47.
73. Vézilier J, Nicot A, Gandon S, Rivero A. Plasmodium infection decreases fecundity and increases survival of mosquitoes. Proc R Soc B Biol Sci. 2012;279:4033-41.

74. Joy TK, Arik AJ, Corby-Harris V, Johnson AA, Riehle MA. The impact of larval and adult dietary restriction on lifespan, reproduction and growth in the mosquito Aedes aegypti. Exp Gerontol. 2010;45:685-90.

75. Pakpour N, Akman-Anderson L, Vodovotz Y, Luckhart S. The effects of ingested mammalian blood factors on vector arthropod immunity and physiology. Microbes Infect. 2013;15:243-54.

76. Ohm JR, Teeple J, Nelson WA, Thomas MB, Read AF, Cator LJ. Fitness consequences of altered feeding behavior in immune-challenged mosquitoes. Parasites Vectors. 2016;9:113.

77. Briegel H, Kaiser C. Life-span of mosquitoes (Culicidae, Diptera) under laboratory conditions. Gerontologia. 1973;19:240-9.

78. Gary RE, Foster WA. Effects of available sugar on the reproductive fitness and vectorial capacity of the malaria vector Anopheles gambiae (Diptera: Culicidae). J Med Entomol. 2001;38:22-8.

79. Styer LM, Carey JR, Wang JL, Scott TW. Mosquitoes do senesce: departure from the paradigm of constant mortality. Am J Trop Med Hyg. 2007;76:111-7.

80. Styer LM, Minnick SL, Sun AK, Scott TW. Mortality and reproductive dynamics of Aedes aegypti (Diptera: Culicidae) fed human blood. Vector Borne Zoonotic Dis. 2007;7:86-98.

81. Hardstone MC, Huang X, Harrington LC, Scott JG. Differences in development, glycogen, and lipid content associated with cytochrome P450-mediated permethrin resistance in Culex pipiens quinquefasciatus (Diptera: Culicidae). J Med Entomol. 2010;47:188-98.

82. Oliver S, Brooke BD. The effect of multiple blood-feeding on the longevity and insecticide resistant phenotype in the major malaria vector Anopheles arabiensis (Diptera: Culicidae). Parasites Vectors. 2014;7:390.

83. Mebrahtu YB, Norem J, Taylor M. Inheritance of larval resistance to permethrin in Aedes aegypti and association with sex ratio distortion and life history variation. Am J Trop Med Hyg. 1997;56:456-65.

84. Di Luca M, Severini F, Toma L, Boccolini D, Romi R, Remoli ME, et al. Experimental studies of susceptibility of Italian Aedes albopictus to Zika virus. Euro Surveillance. 2016;21.

85. Guedes DR, Paiva MH, Donato MM, Barbosa PP, Krokovsky L, Rocha SWDS, et al. Zika virus replication in the mosquito Culex quinquefasciatus in Brazil. Emerg Microbes Infect. 2017;6:e69.

86. Tesla B, Demakovsky LR, Packiam HS, Mordecai EA, Rodríguez AD, Bonds $\mathrm{MH}$, et al. Estimating the effects of variation in viremia on mosquito susceptibility, infectiousness, and RO of Zika in Aedes aegypti. PLoS Negl Trop Dis. 2018;12:e0006733.

87. Ciota AT, Bialosuknia SM, Zink SD, Brecher M, Ehrbar DJ, Morrissette MN, et al. Effects of Zika virus strain and Aedes mosquito species on vector competence. Emerg Infect Dis. 2017;23:1110-7.

88. Chouin-Carneiro T, Vega-Rua A, Vazeille M, Yebakima A, Girod R, Goindin D, et al. Differential susceptibilities of Aedes aegypti and Aedes albopictus from the americas to Zika virus. PLoS Negl Trop Dis. 2016;10:e0004543.

89. Garcia-Luna SM, Weger-Lucarelli J, Rückert C, Murrieta RA, Young MC, Byas $A D$, et al. Variation in competence for ZIKV transmission by Aedes aegypti and Aedes albopictus in Mexico. PLoS Negl Trop Dis. 2018;12:e0006599.

90. Dutra HL, Rocha MN, Dias FB, Mansur SB, Caragata EP, Moreira LA. Wolbachia blocks currently circulating Zika virus isolates in Brazilian Aedes aegypti mosquitoes. Cell Host Microbe. 2016;19:771-4.

91. Lozano-Fuentes S, Kenney JL, Varnado W, Byrd BD, Burkhalter KL, Savage HM. Susceptibility and vectorial capacity of american Aedes albopictus and Aedes aegypti (Diptera: Culicidae) to american Zika virus strains. J Med Entomol. 2019;56:233-40.

\section{Publisher's Note}

Springer Nature remains neutral with regard to jurisdictional claims in published maps and institutional affiliations. 